\title{
A Economia do Isolamento
}

Flavio da Silveira Bruno ${ }^{1}$

\begin{abstract}
Resumo
Este artigo analisa efeitos da pandemia provocada pela Covid-19 na aceleração de transformações socioeconômicas que têm sido associadas à quarta revolução industrial. 0 artigo sintetiza as características da racionalidade dominante na evolução da economia industrial capitalista tendo por base a teoria schumpeteriana, para mostrar como esta mesma racionalidade atuou na preservação do ambiente natural do capital, condicionando e restringindo a visão de futuro da sociedade. Opondo-se à percepção dominante e contraditória de crescimento infinito com recursos finitos, desenvolve-se um processo de contraponto crítico, baseado em exemplos de títulos de notícias e em dilemas notórios, estabelecidos por autoridades públicas e nas redes sociais. $\mathrm{O}$ artigo conclui que uma nova racionalidade apoiada em critérios humanos de percepção do desenvolvimento poderá emergir devido às mudanças comportamentais produzidas na sociedade pela pandemia.
\end{abstract}

Palavras-chave: COVID-19; Pós-capitalismo; Quarta revolução industrial.

\section{Abstract}

This essay analyzes the effects of the pandemic caused by Covid-19 on the acceleration of socioeconomic changes that have been associated with the fourth industrial revolution. The essay summarizes the characteristics of the dominant rationality in the evolution of the capitalist industrial economy based on the Schumpeterian theory, to show how this same rationality acted in the preservation of the natural environment of capital, conditioning and restricting the vision of society's future. Contrasting the dominant and contradictory perception of infinite growth with finite resources, a process of critical counterpoint is developed, based on examples of news headlines and notorious dilemmas, established by public authorities and social medias. The essay concludes that a new rationality based on human criteria for perception of development may emerge due to the behavioral changes produced in society by the pandemic.

Keywords: COVID-19; Post-capitalism; Fourth industrial revolution.

\footnotetext{
${ }^{1}$ Doutor em Engenharia de Produção - UERJ/Brasil. E-mail: flavio.bruno@ueri.br
} 


\section{INTRODUÇÃO}

A pandemia alterou o comportamento das pessoas, aumentando a distância e a mobilidade sociais. Essas alterações comportamentais estão acelerando mudanças que vêm sendo associadas ao pós-capitalismo (MASON, 2015) e à 4a Revolução Industrial (SCHWAB, 2016; BRUNO, 2017; 2019).

Neste artigo, vamos discutir a inadequação das lógicas econômicas que perduraram até hoje. Tal inadequação para lidar com mudanças tão profundas e com os dilemas éticos que têm sido propostos, pode ser um sinal de uma nova lógica capaz de ordenar todo o aparato da economia industrial capitalista.

A partir da síntese da lógica reducionista econômica de acumulação, apoiados na teoria schumpeteriana, estendemos sua abrangência para as dimensões sociais e culturais e analisamos como a criação de uma natureza própria do capital condiciona as visões de mundo e as subordina à teleologia e ao pragmatismo econômico. Exemplos ilustrativos sugerem o desvirtuamento de propósitos do conceito clássico e neoclássico de desenvolvimento, sobretudo daquele apresentado no pensamento marshalliano.

Nossa conclusão é que a pandemia de COVID-19 tem influído no comportamento social, produzindo mudanças na percepção de valores econômicos, contrapostos aos aspectos humanos que estavam adormecidos. Novas experiências afetivas e sociais indutoras da criação e da reativação de atividades, tanto econômicas quanto não-econômicas, ampliaram o leque de capitais disponíveis para uma melhor distribuição de bem-estar na sociedade.

Este artigo está organizado da seguinte forma. A seção 2 sintetiza o conceito schumpeteriano de fluxo circular, para, inicialmente, confrontar as naturezas estacionária e dinâmica da economia, sinalizando, no entanto, para o fato de que ambas as formas se baseiam em uma mesma matriz lógica de acumulação. A seção 3 apresenta o conceito de civilização capitalista e suas contradições. A seção 4 ilustra as rotinas do isolamento provocado pela pandemia. A seção 5 exemplifica algumas evidências de desvirtuamento do conceito de desenvolvimento por meio do falso dilema que opõe a saúde humana à saúde da economia. $A$ seção 6 discute, brevemente, os papéis da ciência em ação, comprimida pela necessidade de encontrar soluções para a doença, em um ambiente de compressão espaço-temporal e de disseminaçãoo em massa de informações em tempo real. A seção 7 apresenta as bases de uma Economia do Isolamento. 


\section{O FLUXO CIRCULAR DA VIDA ECONÔMICA}

Fluxo Circular da vida econômica é uma abstração proposta por Joseph Schumpeter em sua obra de 1911, A Teoria do Desenvolvimento Econômico (SCHUMPETER, 2011). Schumpeter simplificou a visão dos economistas clássicos e neoclássicos para preparar o terreno de sua tese.

No Fluxo Circular, a produção sempre se baseia na experiência anterior de consumo. 0 que será consumido amanhã, tem de ser produzido hoje com a experiência de ontem.

Nessa lógica simplista, cada cidadão da sociedade deposita o produto de seu trabalho em uma grande pilha, de onde cada um retira o que precisa, de acordo com o valor que recebeu por seu trabalho e com o valor requerido pelo trabalho acumulado no produto que quer consumir. Todos são, dessa forma, consumidores e produtores.

Esta visão econômica é estacionária e tenderia sempre ao equilíbrio, só se alterando dimunuindo ou crescendo - motivada por fatos externos ao sistema econômico, como guerras, pandemias ou aumentos de população. O crescimento da economia, nessa ótica, ocorreria de maneira incremental, adaptativa, assim como o aperfeiçoamento dos sistemas produtivos e as inovações de processos, métodos e produtos.

Basta a leitura do capítulo 7 do livro 4, sobre o crescimento da riqueza, em Princípios de Economia, de Alfred Marshall (MARSHALL, 2009, p.183), para se ter uma noção mais precisa do grau de simplificação que a noção de fluxo circular atrela, mesmo que indiretamente, ao pensamento econômico anterior a Schumpeter.

De qualquer maneira, a simplificação se justifica pela necessidade de contrastar sua teoria do desenvolvimento dinâmico, em um processo evolucionário - em ciclos de expansão e depressão produzidos pelo próprio sistema econômico capitalista - com a interpretação estacionária, nas quais as perturbações seriam eventos raros produzidos por causas externas ao sistema.

A renovação do aparato industrial feita pelas empresas acorrentadas ao Fluxo Circular, onde toda sua energia era consumida pela rotina, só poderia ocorrer de forma incremental, ordenando, nesse ritmo, o crescimento e o desenvolvimento. Por isso, as crises, nas visões clássica e neoclássica, seriam eventos externos indesejáveis. Este é justamente o ponto que Schumpeter quer derrubar com sua teoria: o de que o desenvolvimento econômico, motivado pelo sistema tenderia, a ser gradual, só sendo perturbado por imprevistos e por razões nãoeconômicas.

$\mathrm{Na}$ Teoria do Desenvolvimento Econômico, a economia não apenas cresce, mas se desenvolve, ou seja, se transforma em algo diferente e mais capaz, como um organismo. Esse desenvolvimento ocorre em ondas, semelhantes entre si apenas na alternância entre criação e destruição. 
A inovação de empreendedores, na teoria schumpeteriana, é a energia que, quando liberada, provoca uma reação em cadeia, fechando as empresas estabelecidas e destruindo as estruturas em que floresceram. Schumpeter apoiou-se em trabalhos de economistas como Clement Juglar (JUGLAR, 1862) para formular que as crises resultavam da destruição periódica das estruturas produtivas, levando com elas empregos e renda, e criando recessão econômica temporária. Ou seja, nessa visão, as crises são produzidas pelo próprio sistema econômico, sendo resultado necessário de seu desenvolvimento.

\section{A EVOLUÇÃO CONDICIONADA}

O organismo capitalista precisa das crises. Sem elas, ele não se desenvolve. De maneira simplificada, podemos representar a visão estacionária como um círculo, onde as forças econômicas internas do sistema resultam em uma força centrípeta que obriga a economia a girar em um plano. Se ela se transforma e cresce, tal ocorre por razões externas, por adaptação. Já o desenvolvimento em ondas, este sim, provocaria transformações internas fazendo a economia decolar em outro eixo, como uma hélice.

No entanto, o que queremos observar é que o progresso, se o representarmos no eixo vertical de uma hélice, é também circular em sua projeção lógica no plano. Assim, a evolução do sistema capitalista ocorre, mas mantém sempre a mesma componente centrípeta das condições necessárias para esse progresso. Mas quais seriam essas condições?

Em obra posterior (SCHUMPETER, 2011b, p.121), Schumpeter chamou de civilização capitalista o processo de colonização de todas as atividades e de todos os sistemas de pensamento humano pela lógica econômica. O nosso progresso humano - artístico, cultural, social - instituído pelo sistema econômico capitalista, acaba obedecendo às condições impostas pela racionalidade circular que representamos.

Há diversas contradições na lógica capitalista de civilização. São contradições porque entram em choque com outras formas de entender o mundo que também concorreram para o que chamamos de civilização.

É o que pensa o geógrafo David Harvey, um dos principais críticos atuais do regime de acumulação infinita. Harvey entende que o capitalismo não é contrário à natureza, como sugerem alguns ambientalistas, apenas faz uso dela para criar a sua própria natureza (HARVEY, 2016). Outros autores ratificam a noção de Harvey quando afirmam que "o sistema econômico dominante trata recursos físicos como se fossem infinitos e aprisiona recursos intelectuais como se fossem finitos" (BAUWENS; KOSTAKIS; PAZAITIS, 2019).

É essa natureza do capital que vemos nas propostas de cidades inteligentes (e.g. IBM, 2019; CISCO, 2019), nas formas urbanizadas de viver, onde nosso espaço e nosso tempo são 
divididos de maneira a que nos adaptemos continuamente para atender às finalidades do crescimento infinito da produtividade (BRUNO, 2019).

\section{NOVAS ROTINAS DO ISOLAMENTO}

Para perceber que a racionalidade dominante pode, eventualmente, ser substituída por outra, basta que notemos as diferenças que estamos vivendo em nossas rotinas do isolamento. Mais concentrados espacialmente, mudamos nossas atividades diárias, favorecidos pelo florescimento de negócios nos bairros, andamos mais a pé e usamos mais as bicicletas do que os carros; alteramos o uso de nossos guarda-roupas. Se o teletrabalho e a teleducação se afirmarem como possíveis, uma grande mudança comportamental produzirá uma verdadeira revolução.

Pessoas da mesma família que antes dividiam-se em diferentes locais de trabalho, cinco dias por semana, agora encontram-se reunidas em suas casas. Isso gera interações familiares em grau e em frequência - que haviam sido abandonadas há décadas.

Essas interações criam necessidades de novas utilidades para que possam superar dificuldades pouco experimentadas, pois a divisão do trabalho social é diferente da divisão econômica do trabalho, porque seus objetivos são diferentes. Enquanto o objetivo da segunda é a acumulação de capital, o da primeira é a distribuição dos esforços e dos resultados, segundo parâmetros e categorias socioafetivos, como idade, gênero, identidade e personalidade, por exemplo. A segunda ordena os espaços de maneira muito mais hierárquica, enquanto a primeira impõe limites estabelecidos pela tradição familiar e por aspectos psíquicos e morais.

Esses novos comportamentos sociais despertam utilidades da economia digital que não estavam sendo percebidas, e nem sequer imaginadas, porque o aparato estava sendo guiado pela teleologia da racionalidade econômica. As relações das pessoas com o tempo e o espaço mudam no isolamento.

Se o desenvolvimento econômico ocorre em ciclos de transformação gerados pelo próprio organismo econômico que se transforma enquanto as estruturas de produção são substituídas por novas, as formas e motivações de consumo também mudam, adaptando-se às novas utilidades que são oferecidas sob o perigoso disfarce de inovações. O progresso econômico, impulsionado pela tecnologia do capital, promove progressos sociais, mas, ao mesmo tempo, os subordina à natureza criada pelo sistema. Enquanto isso, as lógicas que buscam a acumulação de capital permanecem imutáveis.

O que nós constatamos ao longo das revoluções industriais é que o progresso tecnológico sempre se subordina a critérios econômicos (cf. SCHUMPETER, 2011a, p.12-15) e não a critérios sociais e valores humanos, se estes não forem economicamente mensuráveis. Podemos inferir que o conhecimento de uma sociedade está sempre à frente das tecnologias que the são 
oferecidas, que temos sempre mais conhecimento do que aquele que o sistema coloca à nossa disposição para resolver problemas e criar bem-estar. Tal defasagem ocorre porque a lógica econômica do capitalismo, sua finalidade, é de acumulação e não de distribuição de benefícios promovidos pelos avanços da ciência e da tecnologia.

O capital não se opõe à natureza, mas a usa para criar a sua própria natureza. 0 desenvolvimento capitalista cria novos ambientes que impõem à sociedade industrial novas necessidades de adaptação. As utilidades criadas pela inovação criam e consolidam, ciclicamente, novas necessidades para adaptação da vida ao ambiente da natureza do capital.

É importante, nesse ponto, que pensemos que, da mesma forma que as máquinas, este sistema racional não tem em si mesmo um objetivo final, uma finalidade, além da acumulação e do crescimento infinitos. Em um processo evolutivo, na natureza, há um aperfeiçoamento do organismo que evolui, mas este aperfeiçoamento é a mera adaptação do organismo ao ambiente, em sua luta de preservação. De certa forma, o sistema de acumulação mimetiza, enquanto condiciona e artificializa, a evolução natural, assumindo um papel de protagonista na determinação automática de políticas, papel que não lhe cabe.

As novas rotinas experimentadas durante a pandemia poderão se constituir no embrião de uma mudança nas políticas econômicas. A intensificação do uso das tecnologias digitais de comunicação e da Internet nas atividades criou capacidades para: (a) comunicação de muitos para muitos; (b) auto-organização e (c) criação e distribuição de valor. Esses são os traços de um novo modo de produção proposto por Bauwens, Kostakis e Pazaitis (2019) que democratizaria a produção, empoderaria as comunidades e priorizaria suas necessidades e talentos.

\section{ALGUMAS EVIDÊNCIAS}

A racionalidade dominante - acumulativa, eficiente e produtiva - se estende a outros domínios, como a cultura, as artes, as relações sociais, o trabalho, as profissões, a educação e a saúde, reformando e subjugando, continuamente, o papel da política e do próprio estado.

Vamos avaliar como essa racionalidade parcial e circunstcrita ao pensamento acumulativo aplicada em certas dimensões da vida, simplesmente não faz sentido. Para exemplificar a colonização reducionista de nossa visão de mundo, apresentaremos alguns títulos de artigos de jornais durante a pandemia. Em seguida, analisaremos alguns falsos dilemas notoriamente debatidos nas redes sociais e entre autoridades públicas. 


\subsection{NOTÍCIAS DE JORNAIS}

Alguns títulos de notícias do início da pandemia foram selecionados para ilustrar o pensamento condicionado pela lógica econômica.

Título 1: "País já tem $R \$ 2,2$ bilhões em doações para o combate ao coronavirus" (O Globo, 14/04/2020)

Os bancos, em meio à mais grave crise econômica do século XXI, doaram bilhões para o SUS. A questão que tal expressiva disposição suscita é porque essas doações não ocorreram quando a economia estava melhor e com ótimas perspectivas de crescimento futuro. Se o progresso econômico tem por finalidade melhorar a qualidade de vida e promover a sociedade a um outro patamar de civilização, porque o SUS não foi ajudado quando pessoas morriam nas ruas à espera de atendimento e quando não havia crise econômica, mas é ajudado agora, em situação de penúria?

Uma resposta coerente associaria ao objetivo dessas doações, a salação do sistema econômico e de sua racionalidade dominante. Neste momento, a saúde da população mais pobre é percebida pelos estrategistas econômicos como um fator que interfere na política econômica, à qual os bancos estão associados; nas situações anteriores, não.

Título 2: "Presidente do $B C$ diz a investidores que reduzir mortes por coronavirus é pior para a economia" (The Intercept, 16/04/2020).

Mais um exemplo explícito da aplicação da racionalidade parcial e circunscrita à economia de acumulação e de crescimento infinitos. Não há sequer o questionamento, o movimento intelectual, para buscar um entendimento mais elaborado, que considere a complexidade da nova situação, que saia em busca, pelo menos, das novas variáveis que estão sendo trazidas. Apenas repete-se a mesma fórmula. É a afirmação da moral econômica.

Título 3: "Less globalization, more automation: the economics crisis induced by pandemic is likely to encourage a surge of labour-replacing technology" (The Economist, 22/04/2020).

Como sempre ocorreu, diante da destruição criativa das estruturas de produção e consumo anteriores, o motor da economia acelera sua rotação. A questão é que, dessa vez, são as mudanças sociais que contêm os genes da inovação, são elas que estão estabelecendo o ambiente para novos empreendedores aparecerem. É sempre bom lembrar que um jardim só se mantém com suas espécies se as espécies indesejadas forem sistematicamente eliminadas pelo 
jardineiro. Para a natureza, não existem ervas daninhas. É o que ocorre com a estrutura produtiva de um país onde o jardineiro é o governo e suas ferramentas são o protecionismo das empresas e atividades existentes, mesmo que muitos setores sejam nocivos ou incompatíveis com o desenvolvimento da sociedade.

Há autores que acreditam que a automação ameaça mais as profissões de engenheiros, advogados e médicos do que as de trabalhadores braçais, simplesmente porque é mais fácil automatizar o trabalho intelectual do que encher as fábricas de robôs (e.g. FORD, 2012). Essas interpretações, entretanto, ainda não foram sequer abordadas entre as justificativas para uma ampla revisão do pensamento econômico dominante.

De fato, a globalização é um dos fenômenos que postergou a evolução da automação, enquanto foi possível encontrar trabalho barato em algum canto do mundo. A COVID-19 causou danos à globalização que dificilmente poderão ser reparados, porque mudou a forma das pessoas entenderem o sistema, reduziu sua confiança na possibilidade de que um dia sejam também vencedoras, se para isso é preciso apostar a própria vida.

Título 4: "Winners from the pandemic Big tech's covid-19 opportunity" (The Economist, 040/04/2020).

A busca de oportunidades de acumulação de capital em meio a uma pandemia de proporções tão trágicas seria uma atitude inadequada se não fosse medíocre. O que está acontecendo de realmente novo, aos nossos olhos, é o surgimento de novas experiências em empresas pequenas, pulverizadas, localizadas, de novas experiências de atendimento de novas necessidades, de utilidades não imaginadas antes para tecnologias que estavam limitadas pelas lógicas restritivas dos ciclos de inovação e de criação sistemática de escassez. Esta visão pulverizada e desconcentradora de capital, no entanto, se opõe ao falso dilema entre economia e saúde que encobre as motivações de políticas de curto prazo para a manutenção de poder.

\subsection{ACHATAMENTO DA COMPREENSÃO}

Outra manifestação contraditória, tão debatida por nossos políticos e governantes é o achatamento da curva de disseminação da doença. Na ânsia de defender a lógica de acumulação e de crescimento inifinito, até analistas abrem mão de observar o que está diante de seus olhos. As áreas sob as curvas sem isolamento social e com isolamento só seriam iguais, ou seja, representariam o mesmo acumulado de necessidades de tratamento pela COVID19, se fixarmos o conhecimento como uma constante, e não o considerarmos como uma variável da equação. 
Há inúmeras outras variáveis que condicinam a modelagem teórica de curvas como essas e poucas delas estiveram presentes nas análises e nos debates que confrontavam, e que ainda confrontam, os efeitos benéficos das medidas de isolamento social com as perdas que adviriam da deterioração econômica provocada pela recessão.

Com o tempo, as pessoas mudam sua compreensão das coisas, e mudam de comportamento. Com o tempo a ciência descobre tratamentos e vacinas. Portanto, a questão nunca foi apenas achatar a curva para que as necessidades dos doentes não ultrapassassem as capacidades do sistema de saúde. A questão é, também, de natureza ética: é preciso aumentar suficientemente o tempo em que ocorre a disseminação da doença para garantir a máxima proteção compatível com os recursos de conhecimento disponíveis e, assim, evitar que pessoas percam a vida quando havia recursos morais, intelectuais, tecnológicos e políticos para salvá-las.

Talvez a principal diferença entre esta pandemia e outras ocorridas na história seja o grau de acesso e a quantidade de informação que está disponível e que é acessada, em tempo real, por uma grande quantidade de pessoas. A diversidade de fontes, o acompanhamento da gênese do conhecimento, das contradições, da influência das visões de mundo na construção da verdade e no entendimento da realidade, são oportunidades distribuídas, mundialmente, a um grande número de pessoas, de uma forma inabitual que nunca antes havia sido conseguida ou sequer tentada. As formas tradicionais de informação sempre excluíram a maioria, por considerá-la inepta para participar da solução dos problemas que a afligem. $O$ isolamento social em massa não resultou de imposição de governantes, mas do acesso das massas à informação e a dados primários, em tempo real. A informação circulando livremente pela sociedade, e sendo tratada empiricamente nas redes sociais, reduz a obediência cega à autoridade.

\section{A CIÊNCIA EM AÇÃO}

A ciência é conhecida de maneira rudimentar como o reino das experiências controladas, das teorias, das leis e das equações matemáticas. Muitos a consideram ineficiente, porque insubordinada ao mundo da produtividade econômica. Os cientistas são vistos, pelo senso comum, como desconectados da realidade, em seus laboratórios, longes das necessidades das empresas.

A pandemia está mostrando que as coisas não são bem assim. O medo da morte tem feito com que muitos depositem, apenas na ciência, sua esperanca de sobreviver ao vírus. A própria ciência tem deixado de mão seus protocolos, seus procedimentos rígidos de verificação, seus tempos naturais, para oferecer conhecimentos novos, assumindo riscos maiores em benefício dos ganhos de compartilhamento maciço das informações. Em vez de experiências controladas em laboratório, experiências abertas. Em vez de equações, algoritmos. 
Esta postura da Ciência em Ação ainda não está muito bem entendida pelos leigos. Se uma pessoa sai de casa e não se contamina, sua confiança aumenta. Então, ela aumenta a frequência de saídas. Neste tempo, a disseminação aumentou também seu risco de contrair a doença. Sua confiança tem relação direta com o risco. Portanto, quanto maior o tempo de isolamento, menor a probabilidade de contaminação no seu grupo e maior o conhecimento disponível sobre tratamentos e curas.

O efeito Dunning-Kruger (KUGER; DUNNING, 1999) se refere à forma como nossa autoconfiança varia de acordo com o conhecimento que temos sobre as complexidades que nos envolvem. A ignorância da nossa ignorância nos torna plenos de confiança. Quando conhecemos mais a respeito das coisas, passamos a basear nossa confiança em nossa capacidade de análise da situação.

O conhecimento é um ativo que se multiplica e se desenvolve com o tempo e o uso. É, portanto, um recurso que não obedece aos critérios econômicos de desgaste e depreciação com o tempo. Na lógica econômica de acumulação, o conhecimento já disponível sempre se subordinou aos critérios econômicos para ser realizado, ou seja, à demonstração de capacidade de produzir acumulação econômica.

Buckminster Fuller (FULLER; KUROMIYA,1982) representou a "knowledge-doubling curve" para estimar como novos conhecimentos que haviam dobrado a cada século, até 1900 , dobrariam a cada 18 meses. A IBM, posteriormente, contribuiu para a extrapolação da curva de Buckminster a partir de 1982 até os dias de hoje. Associando esta dinâmica à exponencialização do desenvolvimento tecnológico analisada por Ford (2012), nos damos conta de que é a lógica conservadora e circular da Economia que deve se subordinar à dinâmica multidimensional do Conhecimento e às suas formas de criação de valor.

Voltando ao caso da pandemia, quanto maior o tempo disponível, maior o conhecimento e menores as áreas sob as curvas de mortes acumuladas, portanto, há um falso dilema entre economia e saúde.

\section{A ECONOMIA DO ISOLAMENTO}

Em levantamento mundial recente, a consultoria McKinsey (2020) concluiu que a COVID19 adiantou a adoção de tecnologias em diversos anos, e que muitas das mudanças observadas, tanto no nível organizacional quanto no industrial, são consideradas pelos executivos como consolidadas, ou seja, sem possibilidade de retorno ao estado que vigorava antes da pandemia. A aceleração da transformação digital das empresas em todo o mundo - incluindo a ênfase nas relações entre produção e consumo - é um dos vetores associados à quarta revolução digital e que tem sido, inequivocamente, mobilizado pelas condições impostas pela COVID-19. 
É preciso observar que a digitalização de processos de criação e de realização de valor no sistema capitalista permite alterar teorias e conceitos econômicos resilientes ao longo da evolução do capitalismo industrial, como utilidade e custos marginais, limites da firma e custos de transação, economias de escala, monopolização de ativos escassos, entre outros, em geral dependentes das limitações espaço-temporais que são pulverizadas pela virtualização de grande parte do processo de produção e consumo (cf. BRUNO, 2019).

$\mathrm{O}$ isolamento tem atuado sobre as lógicas centenárias de acumulação porque alterou pelo menos ao longo desses meses - os comportamentos humanos. Mudanças espaço-temporais na mobilidade e nas interações físicas entre pessoas e coisas impactam nas formas de organização da produção, do comércio, da distribuição e do consumo.

Se mudarem as formas com que a economia se realiza no mundo da vida, mudarão também as maneiras de ver o papel e a função da economia em nosso mundo.

A pandemia atuou como uma máquina do tempo. É como se as forças evolutivas - sociais e biológicas - da espécie tivessem agido em meses - e não em séculos ou milênios -, produzindo mudanças radicais - físicas e culturais - nos comportamentos das pessoas, não apenas nas empresas, como revelou o levantamento da McKinsey.

A economia evolui porque esta é sua função na regulação entre a produção de utilidades e as necessidades do consumo. Na recente história econômica do capitalismo, a economia sempre se adaptou para aproveitar as mudanças socioculturais. Ao longo das revoluções industriais, as demandas de consumo se desenvolveram muito além das necessidades básicas impostas pela natureza.

Alfred Marshall (2009) observou que, em seu processo civilizatório, a humanidade inverteu causa e efeito entre a criação de atividades e a satisfação de necessidades. Para o economista neoclássico, a busca por novos conhecimentos criava, sistematicamente, novas atividades que produziam utulidades antes não percebidas pelos consumidores. Mas Marshall também sugeriu que novas necessidades são estimuladas pela satisfação de necessidades em grau inferior. Necessidades latentes impostas pela natureza criada pelo próprio sistema econômico é que sempre propiciaram a busca incessante por inovações, e que resultaram nas ondas capitalistas de desenvolvimento. O que estamos vivendo são imposições do sistema humano ao funcionamento dos sistemas de produção. É uma mudança de paradigma, onde os valores e princípios éticos vencem a hierarquia da lógica econômica.

Por isso, as reações dos atores econômicos dominantes e de seus representantes que temos observado, sobretudo nas democracias lideradas por uma racionalização simplista da vida, porque orientada meramente para o funcionamento do sistema de acumulação de capital econômico. No entanto, essas reações pouco diferem de outras reações observadas em todas as outras revoluções industriais. 
Nas outras revoluções - ou seja, nos outros ciclos de expansão e recessão provocadas pela ruptura das estruturas dominantes - as empresas presas ao fluxo circular também foram superadas pelas inovadoras, essas, como já dissemos, capazes de criar valor a partir da oferta de novas utilidades que induziam novas necessidades e que mudavam o perfil da sociedade. Há uma grande semelhança entre os dois processos. Dessa vez, no entanto, parecem ser as imposições de novos critérios de projeto, dadas pela sociedade, que parecem fomentar a revolução e a destruição da antiga filosofia econômica e industrial. Se nas revoluções anteriores, os empreendedores, ou seja, os agentes econômicos da inovação tecnológica, destruíam os ganhos das estruturas dominantes, dessa vez, é a socidade, inserida simbioticamente no sistema, que poderá provocar a grande transformação.

As novas linhagens e os novos agentes econômicos estão sendo criados pela transformação digital do mundo em consonância com as experiências sociais no isolamento. A verdadeira questão é se as novas experiências sociais de consumo que estão orientando a produção de utilidades sucumbirão ao antigo paradigma da produtividade infinita ou estabelecerão um novo, quando a pressão da doença esvanecer.

Precisaremos estar atentos ao aparecimento de novas empresas sob uma nova matriz lógica, mais complexa, que considere variáveis de desempenho antes negligenciadas, e que leva em conta critérios antes ignorados, na criação de valor e de riqueza a partir de uma melhor e mais justa distribuição de bem-estar no tempo presente, não em um futuro sempre postergado pelas justificativas de curto prazo, de defesa de uma lógica incongruente com o conhecimento disponível.

Uma outra forma de entender o mundo novo pode ser exemplificada pela ansiedade demonstrada por alunos durante a paralisação das aulas. As demonstrações de angústia e de ansiedade com a perda de tempo em sua formação e a constatação de que seu planejamento de futuro estaria comprometido devido à paralisação de atividades escolares, impede o desvendamento de uma oportunidade única.

Há quem acredite que o mundo do trabalho nunca mais retornará a ser como antes (GRANT, 2020). Se esta visão se concretizar, o futuro que planejaram, poderá não existir mais. Eles têm, portanto, a chance de aprender coisas que não teriam tempo, agora, por causa das aulas, e que não teriam tempo depois, quando estiverem trabalhando.

São oportunidades de traçar novos rumos e novas narrativas para as profissões que a quarta revolução industrial irá criar e de se distanciar das profissões que ela irá destruir. Por exemplo, aprendendo uma língua ou se capacitando em cursos online gratuitos, como o "Algoritmos", de Princeton, com 4,9 pontos em 5,0, em 6.598 avaliações. 


\section{CONCLUSÃO}

Em nossa hipótese de trabalho, a Economia do Isolamento resultaria da aceleração dos fatores que povocariam uma nova revolução industrial dissociada, inteiramente, das lógicas de acumulação e de crescimento infinitos que foram estabelecidas pelas revoluções anteriores.

Procuramos sintetizar a matriz lógica que se mostrou resiliente ao longo dos últimos séculos de consolidação do sistema econômico capitalista, a partir da teoria schumpeteriana. Em nossa síntese, estendemos a abrangência dessa matriz a aspectos sociais e culturais e à criação de uma natureza do capital que condiciona as visões de mundo, influindo nos valores éticos e morais da sociedade, pois os subordina à teleologia e ao pragmatismo econômico.

A partir de exemplos ilustrativos, procuramos mostrar sinais dessa desorientação e do desvirtuamento de propósitos do que alguns dos principais economistas clássicos e neoclássicos da história do pensamento econômico entendiam por desenvolvimento.

Concluímos que a pandemia de COVID-19 produziu mudanças no comportamento social que poderão induzir a percepção de valores e de aspectos humanos que estavam adormecidos. Tais mudanças vieram acompanhadas de novas experiências afetivas e sociais, e levariam à criação e reativação de atividades, tanto econômicas quanto não-econômicas, ampliando o leque de capitais disponíveis para o crescimento da riqueza e para o desenvolvimento da sociedade. 


\section{REFERÊNCIAS}

BAUWENS, Michel; KOSTAKIS, Vasilis; PAZAITIS, Alex. Peer to peer: the commons manifesto. London: University of Westminster Press, 2019.

BRUNO, Flavio S. A quarta revolução industrial do setor têxtil e de confecção: a visão de futuro para 2030. 2 ed. São Paulo: Estação das Letras e Cores, 2017.

BRUNO, Flavio S. A primeira revolução social da indústria e o princípio da concetividade continua. Parcerias Estratégicas, v.24, n.48, jun. 2019.

CISCO. What is a smart city? 2019. Disponível em: https://www.cisco.com/c/en/us/ solutions/industries/smart-connected-communities/what-is-a-smart-city.html

FORD, Martin. The lights in the tunnel: automation, accelerating technology and the economy of the future. S.I , Acculant Publishing, 2009.

GRANT, Adam. The world after COVID-19: Adam Grant on how jobs, bosses and firms may improve after crisis. The Economist, 1 jun. 2020.

HARVEY, David. 17 contradições e o fim do capitalismo. São Paulo: Boitempo Editorial, 2016.

IBM. Smarter cities for smarter growth: how cities can optimize their systems for the talentbased Economy. 2019. Disponivel em: https://www.ibm.com/services/us/gbs/ bus/html/smarter-cities.html

JUGLAR, Clement. Des crises commerciales et de leur retour périodique en France, en Angleterre et aus États Unis. Paris: Guillaumin et Cie Libraires-Éditeurs, 1862.

KRUGER, Justin; DUNNING, David. Unskilled and unaware of it: how difficulties in recognizing one's own incompetence lead to inflated self-assessments. Journal of Personality and Social Psychology, v.77, n.6, p. 1121-1134. CiteSeerX 10.1.1.64.2655. doi:10.1037/00223514.77.6.1121. PMID 10626367. 1999.

FULLER, R. Buckmister; KUROMIYA, Kiyoshi Buckminster. Critical Path. St. Martin's Griffin, 1982. 
MASON, Paul. Pós-capitalismo: um guia para o nosso futuro. Trad. José Geraldo Couto. São Paulo: Cia. Das Letras. 2015.

MARSHALL, Alfred. Principles of economics: unabridged eighth edition. New York: Cosimo. 2009 [1890].

MCKINSEY \& COMPANY. How COVID-19 has pushed companies over the technology tipping point - and transformed business forever. McKinsey Digital and Strategy \& Corporate Finance Practices. October 2020. Disponível em: https://www.mckinsey.com/businessfunctions/strategy-and-corporate-finance/our-insights/how-covid-19-has-pushed-companiesover-the-technology-tipping-point-and-transformed-business-forever. Acesso em 10 out. 2020.

SCHUMPETER, Joseph Alois. Theory of economic development. New Jersey: Transaction Publishers, 2011a.

SCHUMPETER, Joseph Alois. Capitalism, socialism and democracy. London: Harper and Brothers Publishers, 2011b.

SCHWAB, K. A quarta revolução industrial. Tradução de Daniel Moreira Miranda. 1. ed. São Paulo: Edipro, 2016.

SMITH, T.G. Politicizing digital space: theory, the internet, and renewing democracy. London: University of Westminster Press. 2017. 